\title{
Chemische Untersuchung des Danburit vom Scopi in Graubündten.
}

\author{
Von E. Ludwig.
}

(Vorgelegt in der Sitzung am 9. November 1882.)

Ende September d. J.übersandte Herrn Hofrath G. Ts chermak der Mineralhändler H. Ho se us in Basel mehrere Krystalle eines Minerales, welches derselbe als ein für die Schweiz neues Vorkommen bezeichnete, zur näheren Bestimmung. Gemäss den von Herrn Hos eus gemachten Mittheilungen wurde dasselbe am Scopi in Graubündten gefunden, wo es in einer Gesteinspalte (im Granit) von erdigem Chlorit umgeben erschien. Das Mineral zeigte sich in den Eigenschaften und im Aussehen von allen bekannten Mineralen abweichend, daher der Einsender dasselbe mit dem neuen Namen Bementit belegte.

In der That ist die Ausbildung der Krystalle nach den Mittheilungen des Herrn Hofrathes Tschermak eine bisher nicht beobachtete, jedoch zeigt sich das Mineral in der Grundform und in dem optischen Verhalten identisch mit dem Danburit von Russel in New-York, welchen vor Kurzem E. Dan a ${ }^{1}$ beschrieben hat.

Auf die Bitte des Herrn Hofrathes Tschermak übersandte Herr Hoseus eine grosse Anzahl von Krystallen zur krystallographischen Bestimmung und eine Quantität kleiner, durchsichtiger Kryställchen für die Analyse.

Ich übernahm die Ausfithrung der chemischen Analyse, Herr Dr. M. Schuster die krystallographischen Messungen.

Nachdem die Arbeit begonnen war, erhielt Herr Hofrath Tschermak von Herm Dr. C. Hintze in Bonn die Nachricht, dass er die Bearbeitung des Danburits vom Scopi unternommen habe. Ich setzte gleichwohl die mit dem so seltenen und präch-

1 Zeitschr. f. Krystallographie V., pag. 183. 
tigen Materiale begonnene Arbeit fort, beendete dieselbe und wartete das Eintreffen der Abhandlung Dr. Hintze's ab. Da in derselben eine Analyse nicht mitgetheilt ist, so habe ich mich entschlossen, die Resultate der von mir vorgenommenen Analyse zu veröffentlichen.

Das von mir zur Analyse verwendete Materiale bestand aus kleinen farblosen, durchsichtigen Krystallsplittern, welche im Institute des Herrn Hofrathes Tschermak mit Sorgfalt ausgesucht waren.

Die Bestimmung des spec. Gewichtes mit Hilfe des Piknometers ergab (bei Verwendung von 2.0845 Grm. Danburit) 2.985 .

Die chemische Prufung ergab als Bestandtheile: Kieselsäure, Borsäure, Kalk, Magnesia und Spuren von Eisen, Mangan und Aluminium. Bei der quantitativen Analyse erhielt ich folgende Werthe:

I. $0.406 \mathrm{Grm}$. der bei $110^{\circ}$ getrockneten Substanz gaben 0.197 Grm. Kieselsüureanhydrid, 0.0935 Grm. Kalk, 0.0037 Grm. pyrophosphorsaure Magnesia, entsprechend 0.0012 Grm. Magnesia und Spuren von Eisenoxyd und Thonerde.

II. 0.398 Grm. der bei $110^{\circ}$ getrockneten Substanz gaben bei der Borsäurebestimmung 0.597 Grm. eines Gemenges von Borsäure, Magnesia und Chlormagnesium zusammen. Aus 0.3674 Grm. dieses Gemenges wurden bei der Magnesiabestimmung erhalten: 0.819 Grm. pyrophosphorsaure Magnesia, ferner aus 0.2296 Grm. des Gemenges bei der Chlorbestimmung: 0.0042 Grm. metallisches Silber. Die Rechnung ergibt somit 0.1147 Grm. Borsäureanhydrid.

Der Analyse gemäss gestaltet sich die procentische Zusammensetzung des untersuchten Minerales, wie folgt:

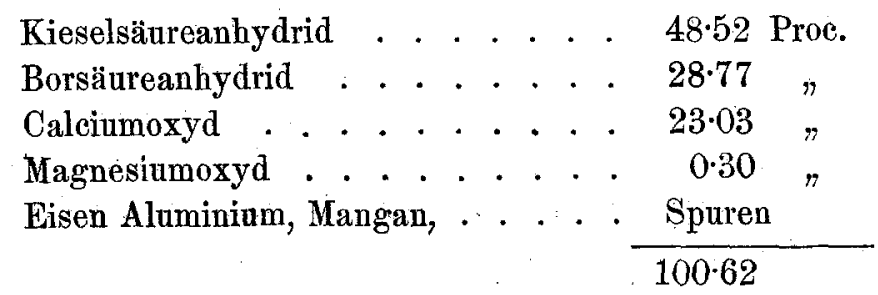

Aus diesen Zahlen ergibt sich durch Rechnung die kleinste Formel $\mathrm{Si}_{8} \mathrm{Bo}_{2} \mathrm{CaO}_{8}$. Die aus der Formel berechneten Werthe 
stimmen, wie die folgende Zusammenstellung zeigt, mit den gefundenen in befriedigender Weise überein:

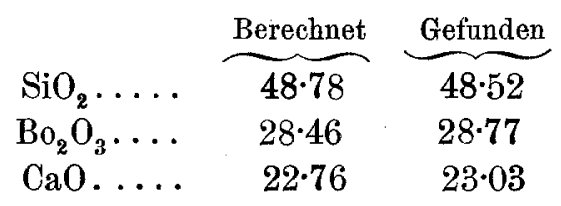

Die chemische Analyse des Minerals vom Scopi hat die Übereinstimmung seiner chemischen Zusammensetzung mit jener des Danburits von Danbury, sowie des Danburits von Russel, St, Lawrence County, New-York ergeben. Die Minerale von diesen beiden Fundorten wurden von Smith und Brush ${ }^{1}$, resp. von Comstock ${ }^{2}$ ) analysirt; ich stelle die von diesen Analytikern erhaltenen Zahlen mit den obigen für den Danburit vom Scopi zusammen:

\begin{tabular}{|c|c|c|c|}
\hline & Danbury & Russel & Scopi \\
\hline $\mathrm{SiO}_{2} \ldots \ldots$ & $48 \cdot 15$ & $48 \cdot 23$ & $48 \cdot 52$ \\
\hline $\mathrm{Bo}_{2} \mathrm{O}_{3} \ldots$ & $27 \cdot 15$ & $26 \cdot 93$ & $28 \cdot 77$ \\
\hline $\mathrm{CaO} \ldots \ldots$ & $22 \cdot 37$ & $23 \cdot 24$ & $23 \cdot 03$ \\
\hline $\mathrm{MgO}$ & $0 \cdot 40$ & - & $0 \cdot 30$ \\
\hline $\mathrm{Al}_{2} \mathrm{O}_{3}+\mathrm{Fe}_{2} \mathrm{O}_{3} \ldots$ & $0 \cdot 30$ & $0 \cdot 47$ & \\
\hline $\mathrm{Mn}_{2} \mathrm{O}_{3} \ldots \ldots$ & 0.56 & - & $S$ \\
\hline T & 0.50 & 0.63. & \\
\hline
\end{tabular}

Der Danburit ist in Hinsicht auf seine chemische Zusammensetzung als die Calciumverbindung einer Borkieselsäure von der Formel $\mathrm{Si}_{2} \mathrm{Bo}_{2} \mathrm{H}_{2} \mathrm{O}_{8}$ zu betrachten; die folgende Structurformel des Danburits trägt dieser Anschauung Rechenschaft:

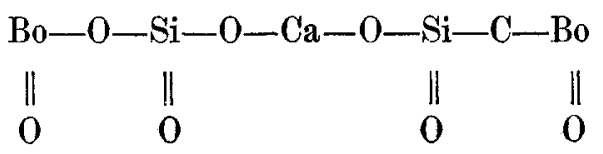

\footnotetext{
1 Am. Journ. 1853 (2), 16, 356.

2 Zeitschr. f. Krystallogr. 5, 189.
} 